\title{
Simulation of a putative susceptibility risk factor to explain the findings of the Heart and Estrogen/progestin Replacement Study (HERS)
}

\author{
Bruce M. Psaty ${ }^{*}$ Mary Cushman ${ }^{\dagger}$ and Frits R. Rosendaal ${ }^{\dagger}$
}

\footnotetext{
* Cardiovascular Health Research Unit, Departments of Medicine, Epidemıology and Health Services, University of Washington, Seattle, WA, USA

+ Departments of Medicine and Pathology, University of Vermont, Burlıngton, VT, USA

† Departments of Clinıcal Epıdemılogy and Hematology, Leiden Universıty Medical Center, Leiden, the Netherlands
}

\begin{abstract}
In the HERS trial, hormone therapy did not reduce the risk of coronary events. In post hoc analyses, treatment was associated with early harm and late benefit. According to one hypothesis, a risk factor may well distinguish a susceptible subgroup with early events associated with hormone therapy from a nonsusceptible subgroup who benefit from hormone therapy. In simulation studies, it appeared that only a susceptibility factor with a low prevalence (3-5\%) and a high risk ratıo (1325 -fold) can produce the pattern of risks seen in HERS. The number of candidate factors is likely to be small.
\end{abstract}

Recerved 25 April 2001, accepted 2 May 2001

Since observational studies have consistently suggested that the use of hormone replacement therapy in postmenopausal women reduces the risk of coronary heart disease, ${ }^{1,2}$ the results of the Heart and Estrogen/progestm Replacement Study (HERS) were unexpected. ${ }^{3}$ In this randomized clinical trial of secondary prevention, combined hormone therapy was no better than placebo at preventing coronary events in postmenopausal women (risk ratıo [RR] $=0.99,95 \%$ confidence interval $[\mathrm{CI}]=0.81-1.22$ ). In post hoc analyses, treatment was associated with a pattern of early harm and late benefit a risk ratio of $1.52(95 \% \mathrm{CI}=1.01-2.29)$ during the first year of follow-up and a risk ratio of $0.75(95 \% \mathrm{CI}=0.50-1.13)$ during follow-up years 4 and 5 .

While chance fluctuations around a null finding of 0.99 remain one important potential explanation, ${ }^{4}$ the HERS investigators offered another broad hypothesis to explain this pattern of risks - the possibility of 'an immediate prothrombotic, proarrhythmic or proischemic effect of treatment that is gradually outweighed by a beneficial effect on the underlyıng progression of atherosclerosis'. ${ }^{3}$ We recently reported an interaction between hormone replacement therapy and the

Correspondence to Bruce M Psaty, MD, PhD, Cardıovascular Health Research Unit, 1730 Minor Avenue, Sulte 1360, Seattle, WA 98101, USA

E-maıl psaty@u washingtonedu prothrombin variant on the risk of myocardial infarction in hypertensive women. ${ }^{5}$ If the hypothesis of an interaction with a risk factor that disposes to early harm is true, there may be a susceptible subgroup who have early events associated with hormone replacement therapy and another nonsusceptible subgroup who benefit from hormone replacement therapy. Identification of such a susceptibility factor would enable clinicians to target hormone therapy to those postmenopausal women who are most likely to benefit and avold using it in those who might experience adverse events. An understanding of the likely characteristics of this hypothetical susceptıbility factor, such as its prevalence and its effect size, might help in the search.

We undertook a series of simulation studies to estimate the prevalence of the susceptible subgroup and, if exposed to hormone replacement therapy, their risk ratıo for coronary events - a combination of prevalence and risk that could reproduce the results of the HERS trial. In all simulations, we assumed that there were 1400 women in each arm of the trial and that the event rate was 30 coronary events per 1000 person-years in the control group. For the effect of oestrogens on risk ratto for coronary events in the nonsusceptible subgroup, we tried several assumptions: (i) risk ratios of 0.9 in year $1,0.8$ in year 2 , and 0.7 in years $3-5$; (I1) risk ratios of $0.75 \mathrm{in}$ all years; and (11i) risk ratios of $0.70 \mathrm{in}$ all years. This furst set of assumptions was based loosely on the lipid-lowering trials, where the 
Table 1 Prevalence and risk ratıo among susceptıbles for hormone-replacement therapy in two simulations

\begin{tabular}{|c|c|c|c|c|c|c|c|c|c|c|}
\hline \multirow[b]{2}{*}{ Prevalence } & \multicolumn{5}{|c|}{ Simulation 1} & \multicolumn{5}{|c|}{ Simulation 2} \\
\hline & $\mathrm{RR}$ & year 1 & year 2 & year 3 & year $4-5$ & $\mathrm{RR}$ & year 1 & year 2 & year 3 & ycar 4-5 \\
\hline & HERS = & 1.52 & 0.98 & 085 & 0.75 & HERS = & 1.52 & 0.98 & 0.85 & 075 \\
\hline 001 & 25 & 114 & 086 & 072 & 070 & 25 & 099 & 081 & 077 & 075 \\
\hline 002 & 25 & 138 & 093 & 073 & 071 & 25 & 123 & 088 & 078 & 076 \\
\hline 003 & 21 & 150 & 103 & 079 & 072 & 25 & 148 & 094 & 080 & 076 \\
\hline 004 & 16 & 150 & 113 & 088 & 077 & 20 & 152 & 107 & 088 & 079 \\
\hline 005 & 13 & 150 & 119 & 095 & 083 & 16 & 151 & 117 & 097 & 084 \\
\hline 006 & 11 & 151 & 123 & 100 & 088 & 13 & 148 & 122 & 105 & 090 \\
\hline 007 & 10 & 154 & 127 & 105 & 092 & 12 & 154 & 128 & 110 & 094 \\
\hline 008 & 9 & 155 & 130 & 109 & 096 & 10 & 149 & 129 & 114 & 100 \\
\hline 009 & 8 & 154 & 132 & 111 & 099 & 9 & 149 & 132 & 118 & 104 \\
\hline 010 & 7 & 151 & 131 & 113 & 102 & 8 & 147 & 133 & 121 & 107 \\
\hline
\end{tabular}

$\mathrm{RR}=$ risk ratıo for coronaty events among the susceptibles exposed to hoi mone ieplacement therapy In simulation 1 , the risk ratıos for coronary events among nonsusceptibles using hormone replacement therapy were assumed to be 09 in year 1,0 8 in year 2, and 07 in years 3-5 In simulation 2, the risk ratios for coronary events among the nonsusceptibles using hormone teplacement therapy were assumed to be 075 in each year Pascal source code and output for the simulations included in the table are avallable on request

survival curves separate only gradually over the first 1-2 years of the trial. ${ }^{6}$

In the simulations, we varied the prevalence of the susceptibllity factor from $1 \%$ to $25 \%$ and the risk ratio for the effect of hormone replacement therapy on the risk of coronary disease from 1 to 25 in the susceptible group. In other words, each simulation included 625 combinations of a prevalence and a risk ratio. For each combination and for each year of follow-up, we calculated the numbers of events and subjects at risk in the treated group and the placebo group, and these numbers were used to estımate the overall risk ratio associated with hormone therapy during each year of follow-up. The event rate in the simulated placebo group was constant. In the simulated hormone replacement therapy group, the total number of events during any one year was the sum of the events in the large group (99-75\%) of nonsusceptibles whose relative risk ranged from 0.9 to 0.7 in the various simulations and the events in the small group (1-25\%) of susceptibles whose relative risk ranged from 2.0 to 25.0 .

Table 1 summarizes the results of two simulations. The top line of Table 1 includes the findings from HERS, which we wished to duplicate in the simulation For each prevalence, one of the 25 simulated risk ratios was selected in an effort to reproduce the year 1 risk of 1.52 and the year 4-5 risk of 0.75 . The question is really this: for which combination of prevalences and risks can the overall findings for the population be at once 1.52 in year 1 and 075 in years 4-5? In Table 1 , the answer is not many. A susceptibility factor with a prevalences of $1-2 \%$, even when risk ratios were 25 , could not attain a year 1 level of risk of 1.52. A susceptibility factor with a prevalence of $3-5 \%$, when the risk ratios were $13-25$, provided perhaps the best fit. For a factor with a prevalence of $6-10 \%$, when the estumated year 1 risks were close to 1.52 , the year $4-$ 5 risks were at or above 0.88 . For prevalences above $10 \%$, the year 4-5-values did not go below 1.0. Assuming the effect of hormone replacement therapy in the nonsusceptible group was 070 across all years shifted the best fit only slightly to prevalences of $4-6 \%$ with risk ratios of 20 to 16 (data not shown).

In this simulation, we assumed that a single fixed factor such as a genetic trait confers an increased coronary risk to a small subgroup who are exposed to hormone replacement therapy while the rest of the population experiences various levels of a modest benefit from hormone replacement therapy. Under this model, it appears that only a factor with a low prevalence and a high risk ratıo can reproduce the pattern of risks seen in HERS. The number of candidate factors that meet these criteria is likely to be small.

This conclusion about the characteristics of the unknown susceptibility factor depends upon several assumptions. We assumed that there was only one susceptibility factor and that its rusk ratıo was constant over tıme. Moreover, we did not take into account a possible variability around these point estimates. Had we done so, the range of potential prevalences and risk ratios would have been larger. Indeed, sampling variability around the null of 0.99 is another reasonable explanation for the HERS findings. The model with a fixed factor would not be appropriate if multiple factors are involved, if the factor is one such as smoking, that may change with tıme, or if physiological adjustments modify the interaction over tume.

\section{Acknowledgements}

The research reported in this article was supported in part by the following grants: 9970178N from the Patient Care and Outcomes Research Program of the American Heart Assoc1ation; HL43201 and HL60739 from the National Heart, Lung and Blood Institute. Dr Psaty is a Merck/SER Clinical Ep1demiology Fellow (co-sponsored by the Merck Co. Foundation, Rahway, NJ, and the Socrety for Epidemiologic Research, Baltimore, MD). 


\section{References}

1 Stampfer MJ, Colditz GA. Estrogen replacement and cotonary heart disease: a quantitative assessment of the epidemiologic evidence. Prev Med 1991; 20: 47-63.

2 Grady D, Rubin SM, Petitt DB et al. Hormone therapy to prevent disease and prolong live in postmenopausal women. Ann Intern Med 1992; 117: 1016-1037.

3 Hulley S, Grady D, Bush T, Furberg C, Herrington D, Riggs B, Vittinghoff E, for the Heart and Estrogen/progestin Replacement Study (HERS) Research Group. Randomızed trial of estrogen plus progestın for secondary prevention of coronary heart disease in postmenopausal women. J Am Med Assoc 1998; 280: 605-613. (Final tables from
http://www.epibiostat.ucsf.edu/HERS/ptable2-5.html; last accessed 8 February 2000.

4 Efron B, Morrıs C. Steın's paradox in statıstıcs. Scl Am 1977; 236(5). 119-127.

5 Psaty BM, Smith NL, Lemaitre RN, Vos HL, Heckbert SR, $\mathrm{LaC}_{101 x} \mathrm{AZ}$, Rosendaal FR. Hormone replacement therapy, prothrombotic mutations, and the risk of incident non-fatal myocardial infarction in post-menopausal women. J Am Med Assoc 2001; 285: 906-913.

6 Scandinavian Sımvastatın Survival Study Group. Randomised trial of cholesterol lowering in 4444 patients with coronary heart disease: the Scandinavian Simvastatin Survival Study (4S). Lancet 1994; 344: 1383-1389. 